\title{
HEALTH EDUCATION: A BABY SHOW AS AN EVALUATION TOOL
}

\section{ID COUPER}

\section{NTRODUCTION}

Health education is an essential ingredient of primary health care but its impact is difficult to evaluate. Where evaluation does occur, the research methods often require major expenditure of manpower, time and money. In addition, despite the importance of incorporating the primary health care goal of promoting participation in health, the subjects of the research often become victims yet again, gaining no visible benefits from the process in a situation where they have many basic needs which are not met.

The baby show is a novel method of assessing the impact of health education.

In the Manguzi health district, in the Ingwavuma district of KwaZulu health education, focused around GOBI-FFF, occurs in a number of different ways: through community health workers, community and school nurses, clinic nurses, doctors, etc. Since 1987, an annual Spring baby competition has been held at Manguzi Hospital to assess the effectiveness of this health education. Any caregiver with a child under 2 years or still breastfeeding is invited to participate. Each participant, after having some demographic details recorded by a staff member, moves to a series of tables where 2 assessors (health workers) give her a score, in the first case based on the Road to Health chart, and in the others based on responses to questions on set topics. Ultimately each entrant receives a prize, related to her score in the competition. The winner receives, inter alia, a sewing machine.

In 1994 there were 7 stations in the competition, which focused on the following areas of knowledge:

1. Road to Health card

2. Nutrition and breastfeeding

3. Preventing dehydration

4. Family planning and AIDS

5. Child growth

6. Immunization

7. Prevention of home accidents

The purpose of this study was to evaluate the relationship of various demographic factors to the scores achieved by entrants in the 1994 competition.

\section{METHODS}

In 1994 the following information was collected from each entrant:
1. Entrant's age

2. Child's age

3. Relationship of entrant to child

4. Educational level

5. Number of children of her own

6. Number of children looked after by the entrant

7. Previous attendance at the Nutrition Education Unit (for caregivers of malnourished children)

8. Number of previous entries to the competition.

The aim was to assess whether there was any correlation between knowledge about child health, as reflected in scores achieved in the baby competition, and issues such as education level, experience with children, and previous preparation, either by attending the education unit or by having participated in the competition previously.

The SAS programme was used to analyze the results.

\section{RESULTS}

There were 215 participants in the 1994 competition, out of an estimated 2500 eligible participants (using delivery numbers). Of these, $203(94.4 \%)$ were mothers of the children entered, 8 were baby sitters $(3.7 \%), 3$ were aunts and 1 was an older sister. The age of the participants was a mean 23.9 years (SD 5.5); the youngest was 12 years old and the oldest 40 years. The age of the children was a mean of 11.3 months (SD 7.2).

The educational level of the caregivers ranged from no formal education $(34,16.0 \%)$ to school leavers' certificate after 12 years of formal schooling $(19,8.9 \%)$; the majority $(126,59.2 \%)$ did not have any secondary schooling. Caregivers had an average of 2.1 children of their own (SD 1.5), with a range of 0 to 8. On average, they looked after slightly more children, a mean of 2.3 (SD 1.6).

Only 29 (13.6\%) had attended the Nutrition Education Unit (NEU). The majority (184, 86.4\%) had never entered the competition before, whereas for $20(9.3 \%)$ it was a second time, $7(3.3 \%)$ a third time, and $2(0.9 \%)$ a fourth time.

The total possible score that could be achieved was 60 points. Variation in points scored ranged from 16 to 56, with a mean of 39.1 (SD 8.3)
Pearson correlation coefficients were computed for the relationship between score on each of the 7 questions and total score on the one hand, and the variables mentioned, namely baby's age, caregiver's age, number of children, and educational level. Correlation was poor in all cases; the only instance where the correlation coefficient was greater than 0.20 was with respect to educational level. In the latter case, the correlation coefficient for the relationship between educational level and total score was 0.44 , still only a moderate correlation. Scatter plotting confirmed the absence of discemible correlations.

T-tests using means were computed to assess the relationship between all other variables and previous attendance at the NEU. The only instance in which there was a significant difference between those who had and had not attended the NEU was in terms of the number of children the caregiver had of her own; those who had attended the NEU had significantly more children $(p=0.03)$.

This analysis suggests that educational level has little impact on health knowledge. Experience in childrearing and/or childminding, and age, also had no discemible effect on knowledge This is similar to the finding of Ross, Loening and Van Middelkoop (1983) that age, parity and level of education had no effect on changes in knowledge about breastfeeding in a similar community.

The relevance of formal education to the life of a rural peasant must be questioned. Life-skills training and heal th education would be of greater value to many rural women that which is presently taught in the classroom.

The fact that entrants who had attended the NEU did not achieve greater scores is of some concem, and calls into question the value of the unit. Similar doubts have recently been expressed about many other such programmes (O'Dwyer and Gillam, 1995). However, the knowledge of caregivers who attended the unit may have been poorer prior to receiving the additional input. A careful evaluation of the Manguzi NEU should be performed.

On the other hand, the generally favourable scores achieved by caregivers of all ages, indicates a fairly high level of knowledge amongst participants. While there is always room for improvement, the results are encouraging. 
The Baby Show provides a useful and community-friendly way of assessing the status of health knowledge amongst some mothers

\section{ACKNOWLEDGEMENT}

My thanks go to Eleanor Gouws of the Medical Research Council in Durban for assistance with the statistical analysis.

\section{REFERENCES}

O'Dwyer M, Gillam SJ.(1995): Children discharged following nutritional rehabilitation: a follow-up study Trop Doct 25(4): 146-151

Ross SM, Loening WEK, Van Middelkoop A. (1983): Breast-feeding evaluation of a health education programme. S Afr Med J 64:361-363.
IAN DOUGLAS COUPER

BA, MBBCh, MFamMed Medical Superintendent Manguzi Hospital,

KwaZulu Natal Department of Health. KwaNgwanase. 